\title{
Extended Twin Study of Alcohol Use in Virginia and Australia
}

\author{
Brad Verhulst, ${ }^{1}$ Michael C. Neale, ${ }^{2}$ Lindon J. Eaves, ${ }^{2}$ Sarah E. Medland, ${ }^{3}$ Andrew C. Heath, ${ }^{4}$ \\ Nicholas G. Martin, ${ }^{3}$ and Hermine H. Maes ${ }^{2}$ \\ ${ }^{1}$ Department of Psychology, Michigan State University, East Lansing, MI, USA \\ ${ }^{2}$ Department of Psychiatry and Department of Human Genetics, Virginia Commonwealth University, Richmond, VA, USA \\ ${ }^{3}$ Department of Genetic Epidemiology, QIMR Berghofer Medical Research Institute, Royal Brisbane Hospital, Brisbane, \\ Australia \\ ${ }^{4}$ Department of Psychiatry Washington University, St. Louis, MO, USA
}

\begin{abstract}
Drinking alcohol is a normal behavior in many societies, and prior studies have demonstrated it has both genetic and environmental sources of variation. Using two very large samples of twins and their first-degree relatives (Australia $\approx 20,000$ individuals from 8,019 families; Virginia $\approx 23,000$ from 6,042 families), we examine whether there are differences: (1) in the genetic and environmental factors that influence four interrelated drinking behaviors (quantity, frequency, age of initiation, and number of drinks in the last week), (2) between the twin-only design and the extended twin design, and (3) the Australian and Virginia samples. We find that while drinking behaviors are interrelated, there are substantial differences in the genetic and environmental architectures across phenotypes. Specifically, drinking quantity, frequency, and number of drinks in the past week have large broad genetic variance components, and smaller but significant environmental variance components, while age of onset is driven exclusively by environmental factors. Further, the twin-only design and the extended twin design come to similar conclusions regarding broad-sense heritability and environmental transmission, but the extended twin models provide a more nuanced perspective. Finally, we find a high level of similarity between the Australian and Virginian samples, especially for the genetic factors. The observed differences, when present, tend to be at the environmental level. Implications for the extended twin model and future directions are discussed.
\end{abstract}

- Keywords: extended twin model, broad-sense heritability, drinking quantity, drinking frequency, age of drinking onset, number of drinks in the last week, broad-sense heritability

Alcohol use is very common in Western societies, with the vast majority (approximately $88 \%$ in the United States and $90 \%$ in Australia) of adults trying alcohol at least once during their lifetime and $71 \%$ of American adults and $83 \%$ of Australian adults drinking in the past year (Australian Institute of Health and Welfare, 2013; Substance Abuse and Mental Health Services Administration, 2012). Furthermore, alcohol-use disorders are among the most common of psychiatric syndromes (Grant, 1997) and are often accompanied by significant psychosocial dysfunction, a range of medical comorbidities, and substantially increased mortality (Secretary of Health and Human Services, 1997). Thinking exclusively about diagnostic thresholds, however, can obscure the subtle gradations of normal alcohol use. Specifically, while approximately $10-15 \%$ of males and $5 \%$ of females qualify for clinical diagnoses of alcohol dependence, overwhelmingly, people who experiment with al- cohol do not go on to develop clinical disorders, making normal drinking a very interesting and important phenomenon to understand. Data from twin studies suggest that most normal alcohol-use behaviors have an important genetic component, but there also appears to be a consistent role for shared environmental factors (Carmelli et al., 1993; Clifford et al., 1984; Gabrielli \& Plomin, 1985; Heath et al., 1989; Heath \& Martin, 1988; Heath, Meyer, Eaves et al., 1991; Heath, Meyer, Jardine et al., 1991; Hopper et al., 1990,1992; Jardine \& Martin, 1984; Kaprio et al., 1982, 1987,

RECEIVED 8 March 2018; ACCEPTED 27 March 2018. First published online 25 April 2018.

ADDRESS FOR CORRESPONDENCE: Brad Verhulst, Michigan State University, 316 Physics Road, Rm 110D, East Lansing Mi, 48824 USA.E-mail: bverhuls@msu.edu 
1991; Koopmans \& Boomsma, 1996; Loehlin, 1972; Maes et al., 1999; Prescott et al., 1994). Similar analyses have not been done with extended pedigrees that provide additional insights and nuances regarding the sources of variation in drinking behaviors. In this paper, we test three primary hypotheses. First, are there differences between four operationalizations of normal drinking phenotypes? Second, do the genetic and environmental variance component estimates from the twin-only model differ from the analogous estimates from the extended twin (ET) model? And third, are there differences in the genetic and environmental factors that contribute to normal drinking behaviors in adults in Australia and Virginia?

\section{Operationalizations of Normal Drinking Phenotypes}

There are several common ways alcohol behaviors have been operationalized in the behavioral genetics literature that could influence the genetic and environmental variance components of the behavior. The two most common operationalizations are how much alcohol is typically consumed by an individual (quantity) and how often an individual drinks alcohol (frequency). Another operationalization of alcohol-related behavior is to assess the number of alcoholic drinks that an individual had in the past week. This is similar to drinking quantity, but when asking people to report the number of drinks that they had in the previous week, there is a more stochastic variation, potentially resulting in larger estimates of the unique environmental variance component, and therefore smaller estimates of the genetic and systematic environmental factors. Finally, it is possible to assess the age of onset, or the individual's age, when they first drank. Previous research suggests that earlier onset of drinking is associated with an increased risk of subsequent alcohol misuse as well as other externalizing behaviors and has a contribution from environmental factors (Hawkins et al., 1992, 1995, 1997; Kandel et al., 1986). Variation in the pattern of genetic and environmental transmission of these behaviors may provide interesting insights into the motivations underlying normal alcohol use (Stallings et al., 1999).

\section{Differences Between the Twin-Only and the Extended Twin Model}

The existing conclusions regarding the genetic epidemiology of alcohol use behaviors are based heavily on twin studies. Twin studies partition the variance of a phenotype into three sources of variance: for normal alcohol phenotype typically additive genetic (A), shared environmental (C), and unique environmental (E) variance components. Including additional collateral relatives, as is done in the ET model, allows for the disaggregation of the genetic and environmental sources of variation into more nuanced mechanisms. In particular, ET design allows the genetic variance component to be broken down into additive genetic (A) and non-additive genetic (D) variance, while the shared environmental variance component is disaggregated into the special twin environment $(\mathrm{T})$, the non-parental environment (S), and intergenerational cultural transmission. This increases the specificity of the source of variance. In addition, simulation studies suggest that the parameters of the twin-only model can be biased due to the fact that in the twin-only model, non-additive genetic variance and shared environmental variance cancel out and appear as additive genetic variance (Keller \& Coventry, 2005). Using more elaborate designs that incorporate information from a variety of different relatives greatly reduces these biases (Keller et al., 2009 , 2010). The reduction in bias, coupled with enhanced specificity of the parameters, implies that the additional complications of extended family models over the classical twin design are worth the additional effort. Finally, the inclusion of spouses (both spouses of the twins and the twins' parents) allows for the estimation of assortative mating (Eaves, 1979; Eaves et al., 1984, 1989; Eaves \& Heath, 1981). As drinking behaviors of spouses are highly correlated, and assortative mating has the potential to inflate the genetic and common environmental variance in twin studies, accounting for spousal correlations will provide more accurate estimates of the variance components. Most of the existing research on the ET models is based upon theoretical expectations and simulation studies. One of the primary questions, therefore, is whether the empirical results from ET design differ from the simple classical twin design and whether the additional parameters add interesting and important insights to our understanding of normal drinking behaviors.

\section{Differences Between Virginia and Australian Samples}

Because we rely on two samples from different countries, it is possible to compare the parameters across samples. The independent samples allow for both a replication of the basic results, and, as there are differences between the alcohol consumption in Australia and the United States, this comparison also speaks to cross-cultural differences in drinking behaviors.

\section{Methods}

\section{Participants}

The data come from two independent samples using virtually the same self-report, mail-back questionnaire. The questionnaires assessed a wide range of health and lifestyle phenotypes. For the current analyses, we restrict our attention to the alcohol-related behaviors. Approximately, 20,000 respondents from 8,019 families in the Australian sample and approximately 23,000 respondents from 6,042 families in the Virginia sample completed the alcohol items in postal surveys conducted between 1985 and 1992. More detailed sampling and participant information can be found in Jardine and Martin (1984) and Lake et al. (2000) for the Australian sample, and in Truett et al. (1994) for the Virginia sample. Due to missing data, the number of respondents for 
TABLE 1

Sample Sizes for Specific Individual Relatives in the Extended Families of Twins for Each Normal Drinking Phenotype in Australia and Virginia

\begin{tabular}{|c|c|c|c|c|c|c|c|c|}
\hline & \multicolumn{4}{|c|}{ Australia } & \multicolumn{4}{|c|}{ Virginia } \\
\hline & Quantity & Frequency & $\begin{array}{l}\text { Age of } \\
\text { onset }\end{array}$ & $\begin{array}{l}\text { Drinks } \\
\text { last week }\end{array}$ & Quantity & Frequency & $\begin{array}{l}\text { Age of } \\
\text { onset }\end{array}$ & $\begin{array}{l}\text { Drinks } \\
\text { last week }\end{array}$ \\
\hline MZ males & 1,700 & 1,682 & 1,083 & 791 & 1,555 & 1,577 & 463 & 1,625 \\
\hline DZ males & 1,229 & 1,224 & 844 & 473 & 1,151 & 1,180 & 406 & 1,216 \\
\hline MZ females & 3,165 & 3,161 & 1,495 & 1,635 & 3,660 & 3,745 & 615 & 3,923 \\
\hline DZ females & 2,064 & 2,071 & 1,050 & 963 & 2,353 & 2,408 & 374 & 2,499 \\
\hline DZ opposite sex & 2,543 & 2,530 & 1,473 & 1,202 & 2,666 & 2,703 & 694 & 2,788 \\
\hline Fathers & 1,273 & 1,275 & 835 & 643 & 756 & 771 & 273 & 800 \\
\hline Mothers & 1,650 & 1,622 & 853 & 711 & 1,132 & 1,163 & 140 & 1,233 \\
\hline Brothers & 1,423 & 1,429 & 854 & 973 & 1,008 & 774 & 388 & 588 \\
\hline Sisters & 1,780 & 1,788 & 776 & 1,066 & 1,491 & 1,048 & 275 & 657 \\
\hline Husbands & 760 & 755 & 217 & 563 & 1,506 & 1,523 & 227 & 1,561 \\
\hline Wives & 1,402 & 1,415 & 748 & 1,100 & 2,169 & 2,193 & 796 & 2,255 \\
\hline Sons & 606 & 612 & 298 & 591 & 1,605 & 1,376 & 712 & 1,052 \\
\hline Daughters & 825 & 824 & 221 & 754 & 2,373 & 1,959 & 671 & 1,284 \\
\hline Total individuals & 20,420 & 20,388 & 10,747 & 11,465 & 23,425 & 22,420 & 6,034 & 21,481 \\
\hline Total families & 8,019 & 6,010 & 4,654 & 3,158 & 5,994 & 6,007 & 3,328 & 6,042 \\
\hline
\end{tabular}

each trait varies. The breakdown of the specific sample size for each phenotype and relative type is presented in Table 1.

In both samples, families were ascertained from twins who provided the names and addresses for their spouses and first-degree relatives (i.e., parents, siblings, and offspring). Taking into consideration all possible familial correlations, there are 88 unique relationships (including cross-sex correlations). These include the relationships between monozygotic (MZ) and dizygotic (DZ) twins, as well as parent-offspring, spouses, and cousins through $\mathrm{MZ}$ and DZ twin parents, to name a few. There is a substantial amount of missing data as no family has a complete record (two parents, two twins, two brothers, two sisters, spouses of both twins, and two sons and daughters of each twin). To address missing data issues, analyses were conducted using full-information maximum likelihood (FIML) for continuous or ordinal data, depending on the trait.

To address intergenerational effects, such as changes in social trends over time, linear and quadratic functions of the respondent's year of birth were included to control for age and cohort differences on the means or thresholds in all of the models. We emphasize, however, that this does not account for age-related changes in the variance residual components.

\section{Measures}

Four separate alcohol-related behaviors were analyzed: drinking quantity, drinking frequency, age at the individual's first alcoholic drink, and the number of alcoholic drinks in the last week. The questions and response options were worded almost identically in the Australian and the Virginia samples. Only the respondents who stated they had previously consumed alcohol were included in the analysis. This excluded less than $2 \%$ of the Australian sample and $4 \%$ of the Virginia sample. Further, in most cases, respondents were asked about the drinking behaviors of their relatives using the same wording, but only the self-reported behaviors are analyzed here.

Drinking quantity. The drinking quantity measure asks: 'Write the number which best describes how many drinks the following people USUALLY have in a TYPICAL WEEK' The respondent is provided with an ordinal scale: none at all, 1-3 drinks, 4-6 drinks, 7-12 drinks, 13-18 drinks, 1924 drinks, 25-42 drinks, 42 or more drinks. In the Australian survey, the last response category was split into two categories, i.e., 43-70 drinks and 70+ drinks, since it was reasoned that heavy drinkers may be unwilling to endorse the highest possible category but would endorse the penultimate.

Drinking frequency. The drinking frequency measure asks: 'Write in the number which best describes how often the following people have had alcoholic drinks in during the past 12 months, or in a typical year if the person is deceased. The response options are as follows: more than once a day, every day, 3-4 times a week, once or twice a week, once or twice a month, less often, and not at all. The question wording and the response options were identical in both surveys.

Age of first drink. The age of onset was measured in slightly different ways in the Australian and Virginia surveys. In Australia, the question was worded: 'At what age did you/your twin first drink alcohol?' The Virginia survey asked a two-part conditional question. The first question asked, 'Have you every drunk alcohol regularly?' and the follow-up question asked, 'If yes, at what age did you start?' The responses for both surveys were discrete ages. If the respondent stated that they started drinking before they were 


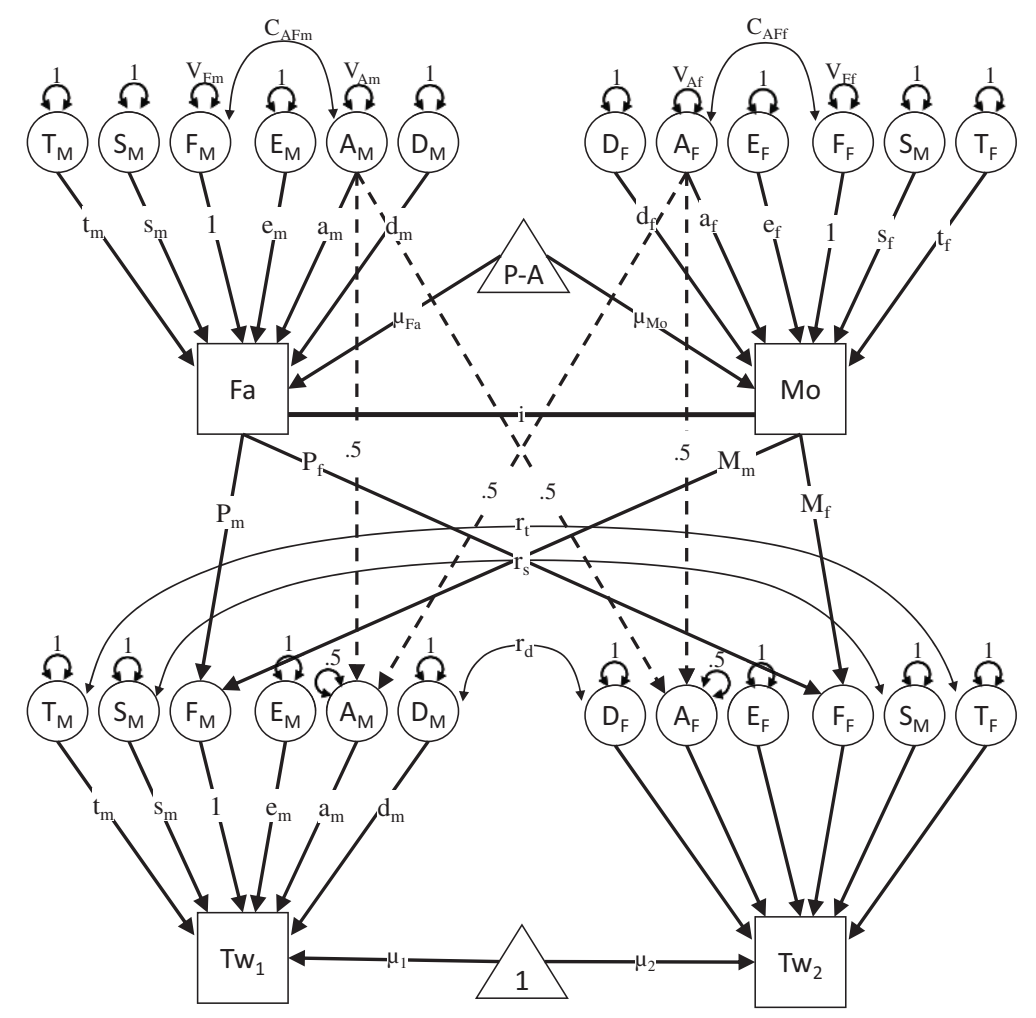

\section{FIGURE 1}

A reduced schematic depiction of the extended twin (ET) model for a DZ opposite-sex twin family with a mother and father. The path model depicts all of the parameters estimated in the ET model, but is restricted to the mother and father of a opposite DZ sex twin pair to simplify the presentation. Squares indicate measured variables, circles indicate latent variables, paths with two arrows indicate variances or covariances, paths with one arrow indicate directional effects, and the co-path (between spouses) is short-hand for the PearsonAitken selection formula. Capital letters indicate latent variables and the corresponding lowercase letters indicate path coefficients. The two sources of genetic variance are additive genetic (A) and non-additive genetic (D) variance. The path between $A$ for the parents and offspring is 0.5 , reflecting the principles of Mendelian inheritance. The variance of $A$ in the parents is $V_{A f}$ and $V_{A m}$ for fathers and mothers, respectively. The residual variance of $A$ in the offspring is 0.5 , reflecting recombination genetic variance. The non-additive genetic factors are uncorrelated between parents and offspring and are correlated at 1 in $M Z$ twins and 0.25 in DZ twins and siblings. The four environmental variance sources are non-parental shared environment, $S$, a special twin environment, $T$, a unique environment, or $\mathrm{E}$, and parent-to-offspring vertical cultural transmissions are shown by the paths Pm (father-son), Pf (father-daughter), Mm (motherson), and Mf (mother-daughter). Spousal correlations are modeled as primary phenotypic assortment, $i$, via the Pearson-Aitken selection formula (Aitken, 1934; Fulker, 1988; Pearson, 1902; Van Eerdewegh, 1982).Passive gene-environment covariation is assessed by $\mathrm{C}_{\mathrm{AFm}}$ and $\mathrm{C}_{\mathrm{AFf}}$ for fathers and mothers, respectively.

8 years old or after they were 40 years old, they were excluded. Various transformations were examined to account for skew, but they did not change the interpretation of the results. Accordingly, the untransformed ages are presented to simplify interpretation.

Number of drinks last week. For both surveys, the number of drinks consumed in the last week, respondents were given a matrix with the type alcoholic drink on the rows and the day of the week on the columns and asked to write in the number of beers, glasses of wine, and drinks of liquor, and in the Australian survey, glasses of sherry and other were also allowed. The number of drinks from each category was summed. As the distribution of this variable is skewed, various transformations were examined but they did not change the interpretation of the results. The untransformed number of drinks is presented to simplify the interpretation.

\section{Statistical Methods}

The path model for the extended twin (ET) design presented in Figure 1 depicts the mother and father of an opposite-sex DZ twin pair but presents all possible parameters that were estimated. The model is described in detail elsewhere (Keller et al., 2009; Maes et al., 1997; Truett et al., 1994), so we limit our discussion here. In the figure, squares indicate measured variables, circles indicate latent variables, paths with two arrows indicate variances or covariances, paths with one arrow indicate causal indicators, and the co-path (between spouses) is shorthand for the Pearson-Aitken selection formula (Aitken, 1934; Fulker, 1988; Pearson, 1902; Van Eerdewegh, 1982). Capital letters indicate latent variables and the corresponding lowercase letters indicate path coefficients.

Two sources of genetic variance are depicted in Figure 1: additive genetic $(A)$ and non-additive genetic $(D)$ variance. 
The path between A for the parents and offspring is fixed at 0.5 , reflecting the principles of Mendelian inheritance. The variance of $\mathrm{A}$ in the parents is $V_{\mathrm{Af}}$ and $V_{\mathrm{Am}}$ for fathers and mothers, respectively. The residual variance of $A$ in the offspring is fixed at 0.5 , reflecting recombination genetic variance. $\mathrm{D}$ is uncorrelated between parents and offspring and is correlated at 1 in $\mathrm{MZ}$ twins and 0.25 in $\mathrm{DZ}$ twins and siblings.

There are four environmental variance sources: a nonparental shared environment $(S)$, a special twin environment $(\mathrm{T})$, a unique environment $(\mathrm{E})$, and parentto-offspring vertical cultural transmission (Pm-fatherson; Pf-father-daughter; Mm-mother-son; and Mfmother-daughter). Cultural transmission allows the parents to 'teach' or directly influence their offspring.

Spousal correlations are modeled as primary phenotypic assortment $(i)$ via the Pearson-Aitken selection formula (Aitken, 1934; Fulker, 1988; Pearson, 1902; Van Eerdewegh, 1982). Primary phenotypic assortment allows the correlation between spouses to be a function of both genetic and environmental causes. We compared the primary phenotypic assortment model to a model with assortment as a function of social homogamy (in which the correlation is primarily a function of shared environmental features as would be found, for example, if spouses primarily met at college) and found no differences between the two models. As phenotypic assortment has fewer implicit assumptions, we present the results from this model. Importantly, geneenvironment covariance is a function of significant vertical cultural transmission and additive genetic variance, possibly augmented by assortment, and it is also included in the model.

Because families include both males and females, all model parameters (except assortment) are estimated separately for males and females, allowing the magnitudes of their effect to differ by sex (quantitative sex differences). The ET model also includes qualitative sex-specific parameters for additive genetic variance, (estimated as malespecific additive genetic variance), non-additive genetic variance, non-parental shared environment, and special twin environments to allow for qualitative sex differences in these sources of variance. As these parameters jointly failed to reach statistical significance in all models, we do not discuss them further.

\section{Model Fitting}

For each alcohol behavior, two analyses were conducted. First, to examine the general pattern of the relationships between family members, correlations between the relatives were estimated. While there are 88 possible unique correlations, the sample sizes on which many of these correlations were based was quite small. To increase the power and focus of the analysis, we combined the correlations between relatives other than twins by sex, leaving 21 correlations for each phenotype. These correlations are presented in Figure 2. Second, we conducted the analysis of the ET model. The model-fitting hypothesis tests are presented in Table 2 and the standardized variance components are presented in Table 3. The unstandardized path coefficients are presented in Table 4. To compare the extended twin models to the estimates of the twin-only design, we estimated a quantitative sex-limitation twin model. All of the models were fitted by maximum-likelihood to the raw data using OpenMx (Boker et al., 2011 , 2012; Neale et al., 2015). Hypothesis tests were conducted using the likelihood ratio test. Likelihood-based confidence intervals are presented (Neale \& Miller, 1997) for the standardized parameters of the full model.

\section{Results}

\section{Correlations Between Relatives for Normal Alcohol Drinking Behaviors}

It is useful to examine the correlations between the various family members before delving into the ET model. These correlations are presented in Figure 2. The Virginian and Australian correlations are represented as circles and squares, respectively, with likelihood-based 95\% confidence intervals. Equivalent familial correlations across samples are banded. Red points depict twin correlations, green points are for first-degree relatives (except DZ twins), brown for second-degree relatives, and blue for relationships through marriage.

The correlations are remarkably consistent across samples. Further, as the genetic relationship between family members decreases there is, generally, a decrease in the magnitude of the correlation, with the exception of the age at first drink. These correlations are consistent with a strong genetic source of variation that we will examine in more detail with the ET model. As expected, for all phenotypes, there are significant spousal correlations, indicative of assortative mating. Interestingly, as the genetic similarity between the twin and the relative decreases, the correlations with the twin's spouse and the relative also decline, implying some degree of gene-environment correlation.

Looking at the correlations across the separate phenotypes provides a cursory test of the differences between different operationalizations of normal drinking behavior. The pattern of correlation for drinking quantity, drinking frequency, and drinking in the last week is quite similar. The major difference between the phenotypes lies with the age of first drink, which is conceptually the most distinct operationalization of a normal drinking behavior. For the age of first drink, the MZ and DZ correlations are very similar, indicating a primarily shared environmental mode of transmission.

The correlations are also consistent across samples, but upon close inspection, there are minor differences between them that require acknowledgment. Specifically, the cousin correlations in the Virginia sample for drinking frequency 


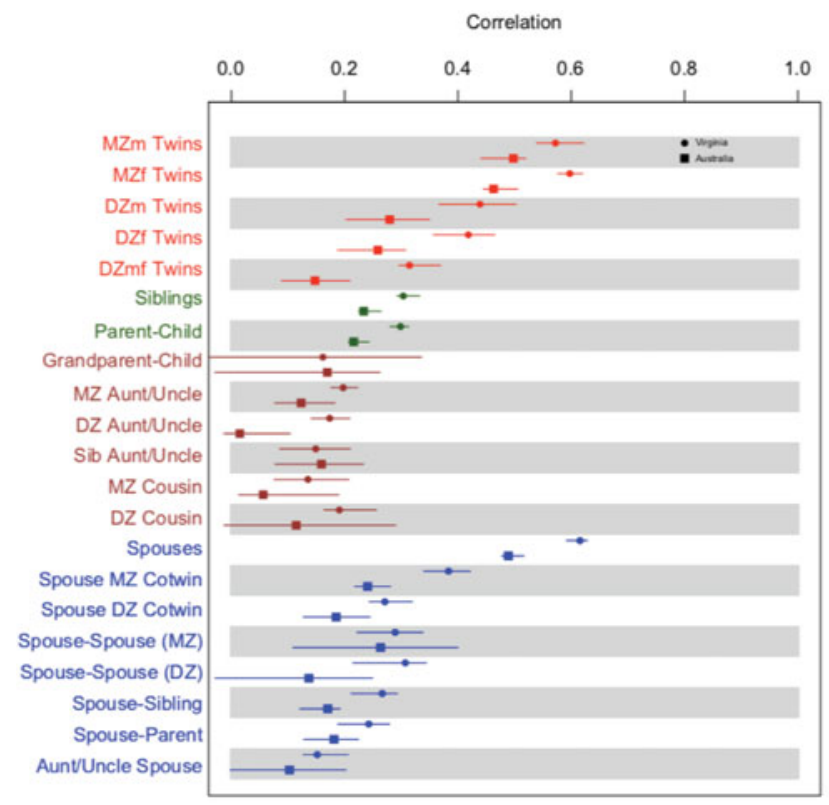

(a) Drinking Quantity

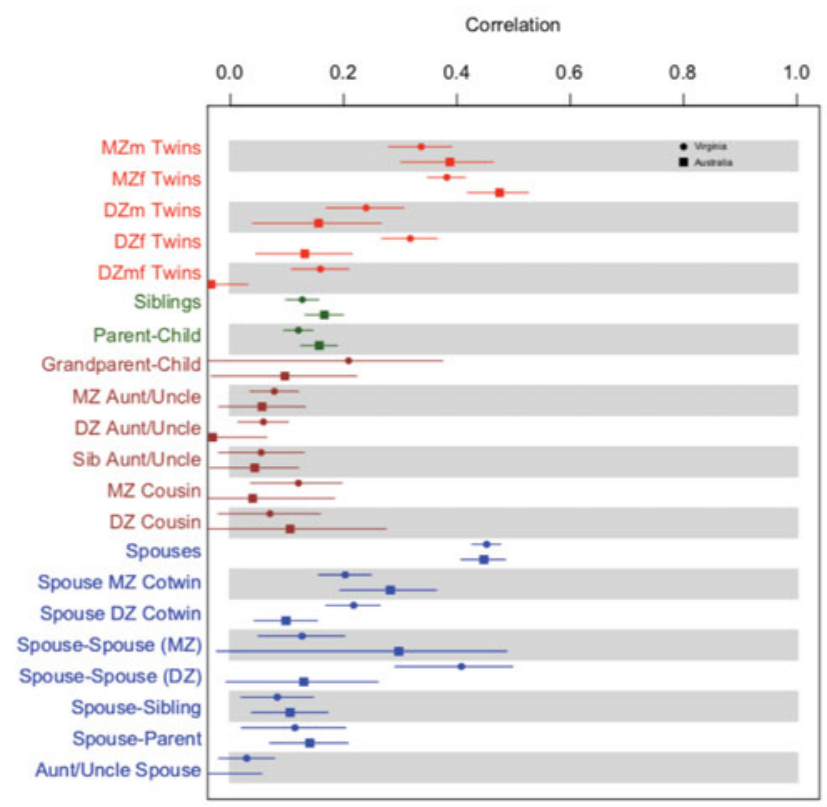

(c) Number of Drinks Last Week

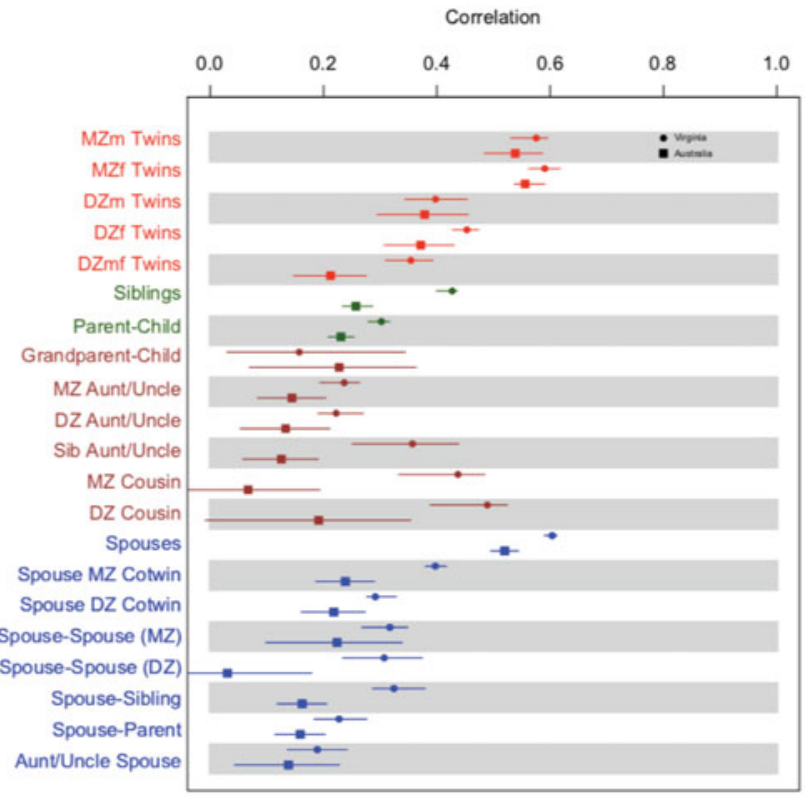

(b) Drinking Frequency

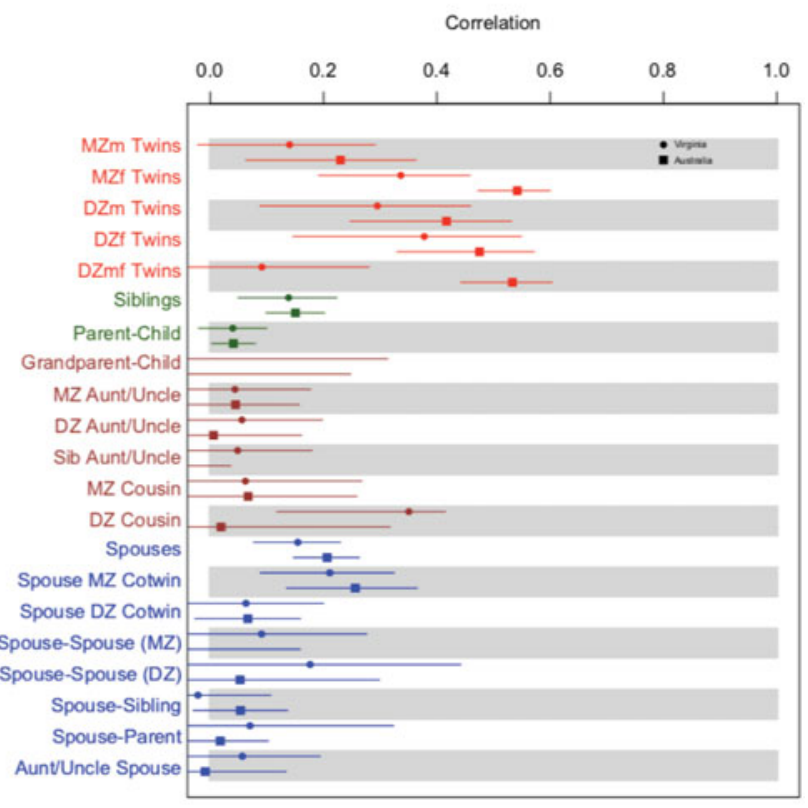

(d) Age of First Drink

\section{FIGURE 2}

(Colour online) Familial correlations for normal alcohol drinking behaviors in Australian and Virginian twin families. Correlations from the Virginia and Australian data are represented by circles and squares, respectively. The horizontal lines dissecting the characters are the likelihood-based $95 \%$ confidence intervals. To increase readability, equivalent correlations across samples are banded in grey or white bands. Color coding is used to group correlations by type, with red for twin correlations, green for first-degree relatives (except DZ twins), brown for second-degree relatives, and blue for relationships through marriage.

are strangely large, albeit with large confidence intervals. In addition, the twin correlations between MZ males for age at first drink appear lower than would be expected, even under a model of transmission dominated by the common environment. In this case, we would expect no difference between the $\mathrm{MZ}$ and $\mathrm{DZ}$ male correlations.

\section{Comparing the Alcohol Drinking Phenotypes}

A series of likelihood ratio tests (LRTs) was used to test statistical hypotheses related to the variance components of the alcohol phenotypes estimated with the ET model. The model fitting results used for hypothesis testing are presented in Table 2. We conclude that a parameter is 
TABLE 2

Model-Fitting Results for Drinking Behaviors

\begin{tabular}{|c|c|c|c|c|c|c|c|c|c|}
\hline & \multirow[b]{2}{*}{$d f$} & \multicolumn{4}{|c|}{ Drinking quantity } & \multicolumn{4}{|c|}{ Drinking frequency } \\
\hline & & \multicolumn{2}{|c|}{ Australia } & \multicolumn{2}{|c|}{ Virginia } & \multicolumn{2}{|c|}{ Australia } & \multicolumn{2}{|c|}{ Virginia } \\
\hline Equate additive genetic & 1 & 5.47 & .02 & 3.81 & .05 & 2.20 & .14 & 2.11 & .15 \\
\hline Equate dominance & 1 & 2.72 & .10 & 4.87 & .03 & 0.69 & .41 & 0.40 & .53 \\
\hline Equate non-parental shared environment & 1 & 0.33 & .57 & 1.39 & .24 & 0.43 & .51 & 0.03 & .87 \\
\hline Equate special twin environment & 1 & 1.42 & .23 & 0.00 & 1.00 & 7.04 & .01 & 6.44 & .01 \\
\hline Equate cultural transmission & 3 & 4.71 & .19 & 5.74 & .13 & 9.72 & .02 & 2.66 & .45 \\
\hline Equate unique environment & 1 & 4.33 & .04 & 3.30 & .07 & 0.02 & .89 & 9.94 & .00 \\
\hline Drop assortment & 1 & 600.82 & .00 & $1,331.86$ & .00 & 993.80 & .00 & $2,053.00$ & .00 \\
\hline Drop additive genetic & 2 & 4.93 & .09 & 10.28 & .01 & 7.34 & .03 & 4.64 & .10 \\
\hline Drop dominance & 2 & 8.31 & .02 & 10.79 & .01 & 3.69 & .16 & 2.64 & .27 \\
\hline Drop non-parental shared environment & 2 & 7.42 & .02 & 25.46 & .00 & 10.70 & .01 & 58.21 & .00 \\
\hline Drop special twin environment & 2 & 1.39 & .50 & 13.21 & .00 & 10.29 & .01 & 6.43 & .04 \\
\hline Drop cultural transmission & 4 & 9.39 & .05 & 11.15 & .03 & 10.11 & .04 & 6.55 & .16 \\
\hline Drop all genetic & 4 & 61.23 & .00 & 86.19 & .00 & 61.95 & .00 & 51.60 & .00 \\
\hline Drop all shared environment & 8 & 18.24 & .02 & 44.05 & .00 & 29.36 & .00 & 85.55 & .00 \\
\hline \multirow[t]{2}{*}{ Drop all familial resemblance } & 12 & $1,014.74$ & .00 & $1,744.67$ & .00 & $1,456.19$ & .00 & $2,158.54$ & .00 \\
\hline & & \multicolumn{4}{|c|}{ Age of first drink } & \multicolumn{4}{|c|}{ Number of drinks last week } \\
\hline Equate additive genetic & 1 & 0.33 & .57 & 0.04 & .83 & 17.32 & .00 & 15.63 & .00 \\
\hline Equate dominance & 1 & 0.00 & 1.00 & 0.00 & 1.00 & 2.84 & .09 & 8.95 & .00 \\
\hline Equate non-parental shared environment & 1 & 1.16 & .28 & 1.60 & .21 & 3.88 & .05 & 0.01 & .92 \\
\hline Equate special twin environment & 1 & 4.36 & .04 & 5.03 & .03 & 0.00 & 1.00 & 3.98 & .05 \\
\hline Equate cultural transmission & 3 & 4.18 & .24 & 2.71 & .44 & 1.83 & .61 & 1.74 & .63 \\
\hline Equate unique environment & 1 & 119.74 & .00 & 0.46 & .50 & 166.16 & .00 & 447.47 & .00 \\
\hline Drop assortment & 1 & 47.35 & .00 & 19.05 & .00 & 294.01 & .00 & 751.74 & .00 \\
\hline Drop additive genetic & 2 & 0.33 & .85 & 0.04 & .98 & 7.56 & .02 & 15.63 & .00 \\
\hline Drop dominance & 2 & 0.00 & 1.00 & 0.00 & 1.00 & 33.07 & .00 & 8.95 & .01 \\
\hline Drop non-parental shared environment & 2 & 36.36 & .00 & 4.01 & .14 & 5.11 & .08 & 28.05 & .00 \\
\hline Drop special twin environment & 2 & 21.62 & .00 & 5.38 & .07 & 0.00 & 1.00 & 41.12 & .00 \\
\hline Drop cultural transmission & 4 & 7.25 & .12 & 2.74 & .60 & 93.04 & .00 & 92.04 & .00 \\
\hline Drop all genetic & 4 & 0.72 & .95 & 0.04 & 1.00 & 110.58 & .00 & 61.61 & .00 \\
\hline Drop all shared environment & 8 & $2,910.26$ & .00 & 15.98 & .04 & 94.44 & .00 & 292.00 & .00 \\
\hline Drop all familial resemblance & 12 & 253.60 & .00 & 60.87 & .00 & 427.96 & .00 & 828.30 & .00 \\
\hline
\end{tabular}

significant if the $p$ value for dropping it from the model is less than 0.05 in both samples. Effectively, a parameter must replicate across samples to be considered significant. The LRTs for all of the phenotypes can be separated into two broad classes: tests of equality of the parameters between the sexes and joint tests of significance of the parameters. The standardized parameters for full ET model are presented in Table 3. The consistency of these hypothesis tests across countries speaks to the similarities and differences across the drinking phenotypes.

Drinking quantity. For drinking quantity, equating A across sex led to a significant reduction in model fit in both samples $\left(\chi_{\text {au }}^{2}=5.47, p_{\mathrm{au}}=0.02 ; \chi_{\text {us }}^{2}=3.81, p_{\mathrm{va}}\right.$ $=0.05$ ), with $\mathrm{A}$ for males being large and statistically significant, $\mathrm{Am}_{\mathrm{au}}=0.33(95 \% \mathrm{CI}[0.27,0.46])$ and $\mathrm{Am}_{\mathrm{va}}=$ 0.36 (95\% CI $[0.27,0.45])$, and smaller and not significant in females, $\mathrm{Af}_{\mathrm{au}}=0.05(95 \% \mathrm{CI}[0.00,0.18])$ and $\mathrm{Af}_{\mathrm{va}}=$ 0.07 (95\% CI $[0.00,0.20])$. D showed the opposite pattern of effects: large and significant in females, $\mathrm{Df}_{\mathrm{au}}=0.25(95 \%$ CI $[0.05,0.35])$ and $\mathrm{Df}_{v a}=0.21(95 \%$ CI $[0.08,0.32])$ and small and non-significant in males, $\mathrm{Dm}_{\mathrm{au}}=0.06(95 \% \mathrm{CI}$ $[0.00,0.29])$ and $\mathrm{Dm}_{\mathrm{va}}=0.01(95 \% \mathrm{CI}[0.00,0.19])$. Importantly, dropping both $\mathrm{A}$ and $\mathrm{D}$ from the model substan- tially reduced model fit $\left(\chi_{\text {au }}^{2}=61.23, p_{\mathrm{au}}<.01 ; \chi^{2}\right.$ va $=$ $\left.61.95, p_{\mathrm{va}}<.01\right)$, implying genetic factors, broadly, have a very large impact on drinking quantity. The non-parental shared environment was significant and could be equated across sex in both samples $\left(\chi_{\text {au }}^{2}=0.33, p_{\text {au }}=.57 ; \chi_{\text {va }}^{2}\right.$ $=0.43, p_{\mathrm{va}}=.24 ; \chi_{\mathrm{au}}=7.42, p_{\mathrm{au}}=0.02 ; \chi_{\mathrm{va}}^{2}=25.46$, $\left.p_{\mathrm{va}}<.01\right)$. The non-parental shared environment had contributed a small amount to the variation in drinking quantity for each sex, $\mathrm{Sm}_{\mathrm{au}}=0.05$ (95\% CI $\left.[0.00,0.14]\right), \mathrm{Sf}_{\mathrm{au}}$ $=0.09(95 \%$ CI $[0.03,0.15]), \mathrm{Sm}_{\mathrm{va}}=0.07(95 \%$ CI $[0.03$, $0.15])$, and $\mathrm{Sf}_{\mathrm{va}}=0.16(95 \% \mathrm{CI}[0.10,0.20])$. None of the other environmental variance components were significant in both samples. Notably, assortative mating was highly significant in both samples $\left(\chi_{\text {au }}^{2}=600.82, p_{\mathrm{au}}<.01 ; \chi_{\mathrm{va}}^{2}=\right.$ $\left.1,331.86, p_{\mathrm{va}}<.01\right)$. Clearly, drinking quantity affects mate choice.

Drinking frequency. For drinking frequency, dropping A or D individually did not significantly reduce the fit of the model in both samples; however, dropping both $\mathrm{A}$ and $\mathrm{D}$ resulted in a substantial decrease in the model fit $\left(\chi_{\text {au }}^{2}\right.$ $\left.=61.95, p_{\mathrm{au}}<.01 ; \chi_{\mathrm{va}}^{2}=51.60, p_{\mathrm{va}}<.01\right)$, implying that genetic factors strongly influence the frequency of alcohol consumption and underscoring the compensatory 
TABLE 3

Standardized Variance Components for Normal Drinking Behaviors

\begin{tabular}{|c|c|c|c|c|c|c|c|c|c|c|c|c|}
\hline & \multicolumn{6}{|c|}{ Australia } & \multicolumn{6}{|c|}{ Virginia } \\
\hline & \multicolumn{3}{|c|}{ Males } & \multicolumn{3}{|c|}{ Females } & \multicolumn{3}{|c|}{ Males } & \multicolumn{3}{|c|}{ Females } \\
\hline & ET & $\Sigma$ & Twin-only & ET & $\Sigma$ & Twin-only & ET & $\Sigma$ & Twin-only & ET & $\Sigma$ & Twin-only \\
\hline \multicolumn{13}{|l|}{ Drinking quantity } \\
\hline Additive genetic (A) & $0.33[0.27,0.46]$ & 0.42 & $0.46[0.28,0.56]$ & $0.05[0.00,0.18]$ & 0.30 & $0.44[0.29,0.51]$ & $0.36[0.27,0.45]$ & 0.43 & $0.25[0.00,0.66]$ & $0.07[0.00,0.20]$ & 0.29 & $0.54[0.04,0.63]$ \\
\hline $\begin{array}{l}\text { Additive genetic via } \\
\text { assortative }\end{array}$ & $0.03[0.00,0.08]$ & & & $0.00[0.00,0.00]$ & & & $0.06[0.01,0.12]$ & & & $0.01[0.00,0.01]$ & & \\
\hline $\begin{array}{l}\text { Non-additive } \\
\text { genetic (D) }\end{array}$ & $0.06[0.00,0.29]$ & & & $0.25[0.05,0.35]$ & & & $0.01[0.00,0.19]$ & & & $0.21[0.08,0.32]$ & & \\
\hline $\begin{array}{l}\text { Unique environment } \\
\text { (E) }\end{array}$ & $0.50[0.43,-0.57]$ & 0.50 & $0.48[0.43,-0.54]$ & $0.55[0.50,-0.60]$ & 0.55 & $0.52[0.48,-0.57]$ & $0.42[0.35,0.49]$ & 0.42 & $0.45[0.39,0.56]$ & $0.42\left[\begin{array}{lll}0.40 & 0.44\end{array}\right]$ & 0.42 & $0.37[0.33,0.45]$ \\
\hline Non-environment (S) & $0.05[0.00,0.14]$ & 0.08 & $0.07[0.00,0.21]$ & $0.09[0.03,0.15]$ & 0.15 & $0.04[0.00,-0.16]$ & $0.07[0.03,0.15]$ & 0.14 & $0.30[0.00,0.54]$ & $0.16[0.10,0.20]$ & 0.29 & $0.09[0.01,0.55]$ \\
\hline $\begin{array}{l}\text { Special twin } \\
\text { environment (T) }\end{array}$ & $0.03[0.00,0.11]$ & & & $0.02[0.00,0.07]$ & & & $0.07[0.03,0.18]$ & & & $0.08[0.01,0.17]$ & & \\
\hline Cultural transmission & $0.00[0.00,0.00]$ & & & $0.03[0.00,0.06]$ & & & $0.00[0.00,0.14]$ & & & $0.03[0.02,0.07]$ & & \\
\hline $\begin{array}{l}\text { Transmission via } \\
\text { assortative }\end{array}$ & $0.00[0.00,0.00]$ & & & $0.01[0.00,0.01]$ & & & $0.00[0.00,0.00]$ & & & $0.02[0.01,0.02]$ & & \\
\hline $\begin{array}{l}\text { Gene-environment } \\
\text { correlation }\end{array}$ & $0.00[0.00,0.02]$ & & & $0.03[0.00,0.04]$ & & & $0.01[-0.08,0.03]$ & & & $0.06[0.05,0.06]$ & & \\
\hline \multicolumn{13}{|l|}{ Drinking frequency } \\
\hline Additive genetic (A) & $0.31[0.04,0.43]$ & 0.42 & $0.49[0.14,0.56]$ & $0.16[0.02,0.35]$ & 0.36 & $0.41[0.24,0.57]$ & $0.29[0.01,0.33]$ & $0.37^{*}$ & $0.53[0.44,0.60]$ & $0.09[0.01,0.26]$ & 0.21 & $0.24[0.13,0.35]$ \\
\hline $\begin{array}{l}\text { Additive genetic via } \\
\text { assortative }\end{array}$ & $0.05[0.01,0.10]$ & & & $0.03[0.00,0.09]$ & & & $0.05[0.00,0.07]$ & & & $0.01[0.00,0.03]$ & & \\
\hline $\begin{array}{r}\text { Non-additive } \\
\text { genetic(D) }\end{array}$ & $0.06[0.00,0.29]$ & & & $0.17[0.00,0.32]$ & & & $0.03[0.00,0.15]$ & & & $0.11[0.10,0.23]$ & & \\
\hline $\begin{array}{l}\text { Unique environment } \\
\text { (E) }\end{array}$ & $0.45[0.38,0.49]$ & 0.45 & $0.48[0.44,0.55]$ & $0.47[0.41,0.51]$ & 0.47 & $0.47[0.43,0.51]$ & $0.43[0.38,0.50]$ & 0.43 & $0.39[0.35,0.44]$ & $0.44[0.43,0.45]$ & $0.44^{*}$ & $0.36[0.33,0.39]$ \\
\hline $\begin{array}{l}\text { Non-parental } \\
\text { environment (S) }\end{array}$ & $0.06[0.01,0.15]$ & 0.13 & $0.02[0.00,0.34]$ & $0.09[0.02,0.16]$ & 0.18 & $0.12[0.00,0.27]$ & $0.18[0.10,0.29]$ & $0.19^{*}$ & $0.08[0.03,0.14]$ & $0.23[0.12,0.29]$ & 0.34 & $0.40[0.29,0.49]$ \\
\hline $\begin{array}{l}\text { Special twin } \\
\text { environment (T) }\end{array}$ & $0.07[0.00,0.18]$ & & & $0.08[0.00,0.16]$ & & & $0.01[0.00,0.03]$ & & & $0.07[0.02,0.15]$ & & \\
\hline Cultural transmission & $0.00[0.00,0.03]$ & & & $0.01[0.00,0.04]$ & & & $0.00[0.00,0.00]$ & & & $0.03[0.00,0.03]$ & & \\
\hline $\begin{array}{l}\text { Transmission via } \\
\text { assortative }\end{array}$ & $0.00[0.00,0.00]$ & & & $0.00[0.00,0.02]$ & & & $0.00[0.00,0.03]$ & & & $0.01[0.01,0.03]$ & & \\
\hline $\begin{array}{l}\text { Gene-environment } \\
\text { correlation } \\
\text { Age at first drink }\end{array}$ & $-0.01[-0.12,0.04]$ & & & $0.03[-0.06,0.05]$ & & & $0.02[-0.01,0.03]$ & & & $0.06[0.04,0.07]$ & & \\
\hline Additive genetic (A) & $0.03[0.00,0.19]$ & 0.03 & $0.00[0.00,0.11]$ & $0.19[0.00,0.38]$ & 0.19 & $0.07[0.00,0.30]$ & $0.01[0.00,0.27]$ & 0.01 & $0.14[0.00,0.36]$ & $0.03[0.00,0.31]$ & 0.03 & $0.10[0.00,0.47]$ \\
\hline $\begin{array}{l}\text { Additive genetic via } \\
\text { assortative }\end{array}$ & $0.00[0.00,0.00]$ & & & $0.00[0.00,0.00]$ & & & $0.00[0.00,0.01]$ & & & $0.00[0.00,0.01]$ & & \\
\hline $\begin{array}{l}\text { Non-additive } \\
\text { genetic (D) }\end{array}$ & $0.00[0.00,0.12]$ & & & $0.00[0.00,0.25]$ & & & $0.00[0.00,0.14]$ & & & $0.00[0.00,0.26]$ & & \\
\hline
\end{tabular}


TABLE 3

Continued

\begin{tabular}{|c|c|c|c|c|c|c|c|c|c|c|c|c|}
\hline & \multicolumn{6}{|c|}{ Australia } & \multicolumn{6}{|c|}{ Virginia } \\
\hline & \multicolumn{3}{|c|}{ Males } & \multicolumn{3}{|c|}{ Females } & \multicolumn{3}{|c|}{ Males } & \multicolumn{3}{|c|}{ Females } \\
\hline & ET & $\Sigma$ & Twin-only & ET & $\Sigma$ & Twin-only & ET & $\Sigma$ & Twin-only & ET & $\Sigma$ & Twin-only \\
\hline $\begin{array}{l}\text { Unique environment } \\
\text { (E) }\end{array}$ & $0.62[0.54,0.71]$ & $0.62^{*}$ & $0.84[0.77,0.91]$ & $0.43[0.37,0.49]$ & 0.43 & $0.45[0.39,0.52]$ & $0.79[0.64,0.89]$ & 0.79 & $0.78[0.64,0.94]$ & $0.63[0.53,0.75]$ & 0.63 & $0.62[0.52,0$. \\
\hline $\begin{array}{l}\text { Non-parental } \\
\text { environment (S) }\end{array}$ & $0.13[0.03,0.21]$ & $0.35^{*}$ & $0.16[0.07,0.22]$ & $0.23[0.10,0.36]$ & $0.37^{*}$ & $0.48[0.45,0.59]$ & $0.20[0.00,0.30]$ & 0.20 & $0.08[0.00,0.33]$ & $0.03[0.00,0.16]$ & 0.34 & $0.28[0.00,0.4$ \\
\hline $\begin{array}{l}\text { Special twin } \\
\text { environment (T) }\end{array}$ & $0.22[0.10,0.33]$ & & & $0.14[0.04,0.26]$ & & & $0.00[0.00,0.11]$ & & & $0.29[0.05,0.43]$ & & \\
\hline Cultural transmission & $0.00[0.00,0.02]$ & & & $0.00[0.00,0.04]$ & & & $0.00[0.00,0.05]$ & & & $0.02[0.00,0.07]$ & & \\
\hline $\begin{array}{l}\text { Transmission via } \\
\text { assortative }\end{array}$ & $0.00[0.00,0.00]$ & & & $0.00[0.00,0.00]$ & & & $0.00[0.00,0.01]$ & & & $0.00[0.00,0.01]$ & & \\
\hline $\begin{array}{l}\text { Gene-environment } \\
\text { correlation }\end{array}$ & $0.00[-0.02,0.00]$ & & & $0.00[-0.04,0.02]$ & & & $0.00[0.00,0.00]$ & & & $0.00[-0.02,0.02]$ & & \\
\hline \multicolumn{13}{|c|}{ Number of drinks last week } \\
\hline $\begin{array}{l}\text { Additive genetic (A) } \\
\text { Additive genetic via } \\
\text { assortative }\end{array}$ & $\begin{array}{l}0.03[0.00,0.08] \\
0.00[0.00,0.00]\end{array}$ & $0.29^{*}$ & $0.05[0.00,0.22]$ & $\begin{array}{l}0.07[0.00,0.17] \\
0.00[0.00,0.02]\end{array}$ & 0.37 & $0.49[0.35,0.60]$ & $\begin{array}{l}0.03[0.00,0.06] \\
0.00[0.00,0.00]\end{array}$ & $0.20^{*}$ & $0.27[0.21,0.33]$ & $\begin{array}{l}0.09[0.00,0.19] \\
0.01[0.00,0.02]\end{array}$ & 0.12 & $0.03[0.00,0$ \\
\hline $\begin{array}{l}\text { Non-additive } \\
\text { genetic (D) }\end{array}$ & $0.26[0.12,0.41]$ & & & $0.30[0.19,0.42]$ & & & $0.17[0.06,0.25]$ & & & $0.02[0.00,0.13]$ & & \\
\hline $\begin{array}{l}\text { Unique environment } \\
\text { (E) }\end{array}$ & $0.68[0.58,0.79]$ & 0.68 & $0.72[0.64,0.81]$ & $0.40[0.30,0.50]$ & 0.40 & $0.46[0.39,0.52]$ & $0.71[0.64,0.82]$ & 0.71 & $0.71[0.67,0.76]$ & $0.62[0.59,0.66]$ & $0.62^{*}$ & $0.40[0.37,0.4]$ \\
\hline $\begin{array}{l}\text { Non-parental } \\
\text { environment (S) }\end{array}$ & $0.01[0.00,0.04]$ & $0.04^{*}$ & $0.23[0.10,0.33]$ & $0.17[0.02,0.34]$ & $0.23^{*}$ & $0.05[0.00,0.17]$ & $0.07[0.02,0.10]$ & $0.09^{*}$ & $0.02[0.00,0.06]$ & $0.01[0.00,0.08]$ & $0.26^{*}$ & $0.57[0.48,0.6$ \\
\hline $\begin{array}{l}\text { Special twin } \\
\text { environment (T) }\end{array}$ & $0.00[0.00,0.01]$ & & & $0.00[0.00,0.04]$ & & & $0.00[0.00,0.06]$ & & & $0.25[0.18,0.31]$ & & \\
\hline $\begin{array}{l}\text { Cultural transmission } \\
\text { Transmission via }\end{array}$ & $\begin{array}{l}0.02[0.00,0.05] \\
0.01[0.00,0.02]\end{array}$ & & & $\begin{array}{l}0.04[0.02,0.08] \\
0.02[0.00,0.03]\end{array}$ & & & $\begin{array}{l}0.02[0.01,0.05] \\
0.00[0.00,0.01]\end{array}$ & & & $\begin{array}{l}0.00[0.00,0.01] \\
0.00[0.00,0.01]\end{array}$ & & \\
\hline Gene-environment & $0.09[-0.06,0.17]$ & & & $-0.22[-0.41,-0.05]$ & & & $0.08[0.03,0.14]$ & & & $0.00[-0.02,0.02]$ & & \\
\hline
\end{tabular}

Gene-environm

Note: The table presents the standardized variance components from the four normal drinking phenotypes, with $95 \%$ likelihood-based confidence intervals for males and females in the Australia and Virginia samples. The $\mathrm{E}$ columns indicate the variance components for the $\mathrm{ET}$ model. A represents additive genetic variance, D represents non-additive genetic variance, $\mathrm{E}$ represents unique environmental variance, $\mathrm{S}$ represents non-additive genetic variance, and T represents variance from the special twin environment. The entries are standardized so that everything in a column except gene-environment correlation sum to 1 , subject to rounding error The twin-only column presents the results from the model where only twins were used to estimate the parameters. The $\Sigma$ column calculates the sum of the broad genetic and environmental components from the ET model. The * beside number from the $\Sigma$ column indicates that the sum of the broad genetic and environmental parameters from the ET model does not fall within the $95 \%$ confidence intervals from the twin model. $95 \%$ confidence intervals in square brackets. 
TABLE 4

Unstandardized Path Coefficients From the Extended Twin Model for Normal Drinking Behaviors in Australia and Virginia

\begin{tabular}{|c|c|c|c|c|c|c|c|c|}
\hline & \multicolumn{2}{|c|}{ Quantity } & \multicolumn{2}{|c|}{ Frequency } & \multicolumn{2}{|c|}{ Age of first drink } & \multicolumn{2}{|c|}{ Drinks in the last week } \\
\hline & Australia & Virginia & Australia & Virginia & Australia & Virginia & Australia & Virginia \\
\hline $\mathrm{Vm}$ & 1.50 & 2.26 & 2.23 & 3.34 & 0.36 & 0.27 & 1.83 & 1.02 \\
\hline $\mathrm{Vf}$ & 1.63 & 2.05 & 2.24 & 2.78 & 0.20 & 0.36 & 0.64 & 0.26 \\
\hline I & $0.31^{\S}$ & $0.29 \S$ & $0.23^{\S}$ & $0.20^{\S}$ & $0.79 \S$ & $0.55^{\S}$ & $0.41^{\S}$ & $0.88^{\S}$ \\
\hline $\mathrm{Am}$ & $0.70^{\ddagger}$ & $0.90^{\ddagger \S}$ & $0.84^{\S}$ & 0.97 & -0.06 & 0.05 & $0.22^{\ddagger \S}$ & $-0.18^{\ddagger \S}$ \\
\hline Af & $0.27^{\ddagger}$ & $0.35^{\ddagger \S}$ & $0.59 \S$ & 0.49 & 0.10 & 0.10 & $-0.24 \pm \S$ & $0.18^{\ddagger \S}$ \\
\hline Sm & $0.26^{\S}$ & $0.39^{\S}$ & $-0.36^{\S}$ & $0.77^{\S}$ & $0.18^{\S}$ & $0.23^{\S}$ & $0.13^{\ddagger \S}$ & $-0.26^{\S}$ \\
\hline$\underline{\mathrm{Sf}}$ & $0.38^{\S}$ & $0.56^{\S}$ & $-0.45^{\S}$ & $0.75^{\S}$ & $0.24^{\S}$ & $0.10^{\S}$ & $0.38^{\neq \S}$ & $-0.27^{\S}$ \\
\hline$\overline{\mathrm{Tm}}$ & 0.22 & $0.40^{\S}$ & $-0.41^{\ddagger \S}$ & $-0.21^{\ddagger \S}$ & $0.30^{\ddagger \S}$ & $0.02^{\ddagger}$ & 0.00 & $0.00^{\ddagger \S}$ \\
\hline $\mathrm{Tf}$ & -0.18 & $0.39^{\S}$ & $0.41^{\ddagger \S}$ & $0.44^{\ddagger \S}$ & $0.20^{\ddagger \S}$ & $0.32^{\ddagger}$ & 0.00 & $0.25^{\ddagger \S}$ \\
\hline $\mathrm{Em}$ & $0.87^{\ddagger}$ & 0.97 & 1.01 & $1.19^{\ddagger}$ & $0.48^{\ddagger}$ & 0.46 & $1.07^{\ddagger}$ & $0.82^{\ddagger}$ \\
\hline$E f$ & $0.93^{\ddagger}$ & 0.91 & 1.01 & $1.07^{\ddagger}$ & $0.30^{\ddagger}$ & 0.48 & $0.58^{\ddagger}$ & $0.47^{\ddagger}$ \\
\hline $\mathrm{Dm}$ & $-0.29 \S$ & $-0.15^{\ddagger \S}$ & 0.35 & 0.32 & 0.00 & 0.00 & $0.66^{\S}$ & $0.40^{\ddagger \S}$ \\
\hline Df & $-0.63^{\S}$ & $0.63^{\ddagger \S}$ & 0.60 & 0.55 & 0.00 & 0.00 & $0.49^{\S}$ & $-0.05^{\ddagger \S}$ \\
\hline $\mathrm{Mm}$ & 0.01 & 0.01 & -0.06 & 0.06 & -0.01 & -0.02 & 0.10 & 0.05 \\
\hline $\mathrm{Pm}$ & -0.01 & 0.01 & 0.03 & 0.00 & 0.10 & -0.02 & 0.12 & 0.13 \\
\hline Mf & $0.16^{\S}$ & $0.16^{\S}$ & 0.06 & $0.15^{\S}$ & 0.05 & $0.14^{\S}$ & $0.17^{\S}$ & 0.09 \\
\hline $\mathrm{Pf}$ & 0.05 & 0.08 & 0.04 & 0.07 & -0.03 & 0.00 & 0.08 & 0.07 \\
\hline$V_{A}$ & 1.09 & 1.18 & 1.17 & 1.17 & 0.99 & 1.00 & 1.03 & 1.01 \\
\hline$C_{\mathrm{AFm}}$ & 0.00 & 0.02 & -0.01 & 0.04 & 0.00 & 0.00 & 0.37 & -0.21 \\
\hline$C_{\mathrm{AFf}}$ & 0.08 & 0.15 & 0.06 & 0.16 & 0.00 & 0.01 & 0.37 & -0.21 \\
\hline$C_{\mathrm{Fm}}$ & 0.00 & 0.00 & 0.01 & 0.01 & 0.00 & 0.00 & 0.04 & 0.02 \\
\hline$C_{\mathrm{Fm}}$ & 0.06 & 0.10 & 0.02 & 0.11 & 0.00 & 0.01 & 0.04 & 0.01 \\
\hline$C_{\mathrm{Fmf}}$ & 0.00 & 0.01 & -0.01 & 0.03 & 0.00 & 0.00 & 0.04 & 0.01 \\
\hline$\mu_{\text {Male twin }}$ & 0.85 & -0.26 & 2.13 & 0.68 & 1.86 & 2.44 & 1.04 & 0.27 \\
\hline$\mu_{\text {Female twin }}$ & 0.25 & -0.67 & 1.15 & 0.14 & 1.42 & 2.40 & 0.59 & 0.22 \\
\hline$\mu_{\text {Father }}$ & 0.99 & -0.44 & 2.33 & 0.36 & 1.68 & 2.28 & 1.15 & 0.21 \\
\hline$\mu_{\text {Mother }}$ & 0.09 & -1.04 & 0.95 & -0.42 & 1.64 & 2.51 & 0.55 & 0.16 \\
\hline$\mu_{\text {Brother }}$ & 0.92 & -0.16 & 2.25 & 1.46 & 1.89 & 2.41 & 1.15 & 0.68 \\
\hline$\mu_{\text {Sister }}$ & 0.19 & -0.68 & 1.05 & 0.85 & 1.36 & 2.32 & 0.55 & 0.50 \\
\hline$\mu_{\text {Wife }}$ & 0.11 & -0.75 & 1.04 & 0.05 & 1.38 & 2.37 & 0.59 & 0.18 \\
\hline$\mu_{\text {Husband }}$ & 0.83 & -0.28 & 2.20 & 0.73 & 1.79 & 2.37 & 1.06 & 0.25 \\
\hline$\mu_{\text {Son }}$ & 0.85 & -0.16 & 2.20 & 1.37 & 2.00 & 2.49 & 1.07 & 0.62 \\
\hline$\mu_{\text {Daughter }}$ & 0.29 & -0.45 & 1.22 & 0.95 & 1.37 & 2.41 & 0.63 & 0.50 \\
\hline$\beta_{\text {Birth (males) }}$ & 0.68 & 2.69 & 2.41 & 4.00 & 0.83 & -0.56 & 0.31 & 0.73 \\
\hline$\beta_{\text {Birth (females) }}$ & 0.91 & 1.86 & 3.72 & 3.78 & 0.40 & 1.79 & 0.04 & 0.06 \\
\hline$\beta_{\text {Birth }}{ }^{2}$ (males) & -0.26 & -2.43 & -3.31 & -4.62 & -2.14 & -0.89 & -0.03 & -0.08 \\
\hline$\beta_{\text {Birth }}{ }^{2}$ (females) & -0.98 & -2.15 & -4.34 & -4.33 & -0.54 & -4.49 & -0.01 & -0.01 \\
\hline Inc 3 & 0.58 & 0.57 & 0.80 & 0.81 & & & & \\
\hline Inc 4 & 0.65 & 0.68 & 1.22 & 0.95 & & & & \\
\hline Inc 5 & 0.40 & 0.50 & 1.00 & 0.83 & & & & \\
\hline Inc 6 & 0.39 & 0.48 & 1.46 & 1.47 & & & & \\
\hline $\operatorname{lnc} 7$ & 0.42 & 0.76 & & & & & & \\
\hline $\operatorname{lnc} 8$ & 0.15 & & & & & & & \\
\hline Estimated parameters & 43 & 42 & 41 & 41 & 37 & 37 & 37 & 37.00 \\
\hline$-2 \mathrm{LL}$ & $66,998.31$ & $59,890.36$ & $67,962.77$ & $73,720.70$ & $15,759.17$ & $9,887.00$ & $32,030.64$ & $42,587.71$ \\
\hline
\end{tabular}

Note: Hypothesis tests were only conducted for the path coefficients (as the means, thresholds, and year of birth regressions are not the focus of the current analyses). As there were two types of significance tests, significant differences between the male and female parameters are indicated by 末, while $\S$ indicates that dropping both parameters from the model significantly reduced the fit. Significance tests were not directly conducted for italicized parameters. To simplify the presentation of the table, the labels used here are the same as those used in Figure 1 . Vm $=$ male variance, $\mathrm{V} f=$ female variance, $i=$ the Pearson-Aitken selection formula for assortative mating, Am = male additive genetic variance, Af = female additive genetic variance, $\mathrm{Dm}=$ male non-additive genetic variance, $\mathrm{Df}=$ female non-additive genetic variance, $\mathrm{Sm}=$ male non-parental shared environmental variance, $\mathrm{Sf}=$ female non-parental shared environmental variance, $\mathrm{Tm}=$ male special twin environment variance, $\mathrm{Tf}=\mathrm{female}$ special twin environment variance, $\mathrm{Em}=$ male unique environmental variance, $\mathrm{Ef}=$ female unique environmental variance. $\mathrm{Mm}, \mathrm{Pm}, \mathrm{Mf}$, and $\mathrm{Pf}$ represent cultural transmission paths from mothers and fathers to sons and daughters, respectively. $V_{A}=$ the inflation of additive genetic variance in parents. $C_{\mathrm{Fm}}$ and $C_{\mathrm{Ff}}=$ the inflation of shared environmental variance in parents. $C_{\mathrm{AFm}}, C_{\mathrm{AFf}}$, and $C_{\mathrm{AFmf}}=$ the covariance between the shared environmental and additive genetic variance in parents. $\mu=$ the respective mean and $\beta=$ the respective regression parameter. Because many of the variables are ordinal, Inc = increment between thresholds.

relationship between estimates of $\mathrm{A}$ and $\mathrm{D}$. The $\mathrm{S}$ variance component consistently related to drinking frequency accounted for a small amount of variance in the Australian sample, $\mathrm{Sm}_{\mathrm{au}}=0.06$ (95\% CI [0.01, 0.15]) and $\mathrm{Sf}_{\mathrm{au}}=0.09$ (95\% CI $[0.02,0.16])$, and a moderate amount of variance in the Virginia sample, $\mathrm{Sm}_{\mathrm{va}}=0.18$ (95\% CI $\left.[0.10,0.29]\right)$ and $\mathrm{Sm}_{\mathrm{va}}=0.23$ (95\% CI $\left.[0.12,0.29]\right)$. Again, the assortative mating parameter is highly significant for both samples, implying that how often an individual drinks alcohol is a major factor in mate choice.

Number of drinks in the past week. While both genetic factors contribute to the number of drinks consumed in the past week, the $\mathrm{D}$ appears to contribute more variance than the A. Specifically, in Australia, the contribution of the non-additive genetic factor is moderate for both sexes, 
$\mathrm{Dm}_{\mathrm{au}}=0.26(95 \% \mathrm{CI}[0.12,0.41])$ and $\mathrm{Df}_{\mathrm{au}}=0.30(95 \% \mathrm{CI}$ $[0.19,0.42])$, and in Virginia, it is slightly smaller for males, $\mathrm{Dm}_{\mathrm{va}}=0.17(95 \% \mathrm{CI}[0.06,0.25])$, but not significant for females, $\mathrm{Df}_{\mathrm{va}}=0.03$ (95\% CI $\left.[0.00,0.13]\right)$. In females, but not males, the environment also contributes to the variance in the number of drinks consumed in the last week, but in Australia, the environmental factors are seen in $\mathrm{S}, \mathrm{Sf}_{\mathrm{au}}=$ 0.17 (95\% CI $[0.02,0.34])$, while in Virginia they are seen in $\mathrm{T}, \mathrm{Tf}_{\mathrm{va}}=0.25(95 \% \mathrm{CI}[0.18,0.31])$. As with the previous phenotypes, the parameter for assortative mating is highly significant.

Age at first drink. The age when people first drank alcohol followed a substantially different pattern of transmission from the other phenotypes. Genetic factors did not contribute to the variance in age of onset in either sample for either $\operatorname{sex}\left(\chi_{\mathrm{au}}^{2}=0.72, p_{\mathrm{au}}=.95 ; \chi^{2} \mathrm{va}=0.04, p_{\mathrm{va}}=\right.$ $1.00)$. Instead, $\mathrm{T}$ and $\mathrm{S}$ were the primary contributors to the phenotypic variance. The environmental parameters, however, were not consistently significant across sexes and samples. In Australia, $\mathrm{S}$ was larger for females, $\mathrm{Sf}_{\mathrm{au}}=0.23(95 \%$ CI $[0.10,0.36])$, than for males, $\mathrm{Sm}_{\mathrm{au}}=0.13$ (95\% CI [0.03, $0.21])$, while $\mathrm{T}$ was larger for males, $\mathrm{Tm}_{\mathrm{au}}=0.22(95 \% \mathrm{CI}$ $[0.10,0.33])$, than for females, $\mathrm{Tf}_{\mathrm{au}}=0.14$ (95\% CI $[0.04$, $0.26])$. Alternatively, in Virginia, $S$ was not significant for either sex $\left(\chi^{2}{ }_{\text {va }}=4.01, p_{\mathrm{va}}=.14\right)$, but T was significant for females, $\mathrm{Tf}_{\mathrm{va}}=0.29(95 \% \mathrm{CI}[0.05,0.43])$. Despite this inconsistency, the joint hypothesis test of all the environmental parameters suggests that environmental factors are strongly related to the age people start drinking $\left(\chi_{\mathrm{au}}^{2}=2,910.26, p_{\mathrm{au}}\right.$ $\left.<.01 ; \chi_{\mathrm{va}}^{2}=15.98, p_{\mathrm{va}}=.04\right)$. Notably, a large proportion of the variance is due to unshared environmental factors. As with the previous phenotypes, the age at first drink was significantly correlated between spouses.

Comparing the ET and twin-only designs. Table 3 provides the standardized variance components for the ET and twin-only designs for each of the four phenotypes. To compare the ET with the twin-only design, the sum of the genetic variance components from the ET model $(A, D$, and A via assortment) was compared with the A component of the twin model and the sum of the systematic environmental components of the ET model (S, T, cultural transmission, and cultural transmission via assortment) was compared with the $\mathrm{C}$ component of the twin model. The $\mathrm{E}$ components were directly compared between the ET and the twin models. Because the ET model uses data from all available relatives, while the twin model only uses data from the twins, the models are not nested. Our test of the difference between the ET and twin-only models, therefore, is whether the sum of the relevant variance components from the ET model falls within the $95 \%$ confidence interval of the corresponding statistic in the twin model.

A brief look at Table 3 shows a high level of consistency between the ET and the twin-only models. Across the four phenotypes in both sexes in the two samples, there are 48 comparisons between the classical twin model and the ET model (four phenotypes $\times$ two samples $\times$ two sexes $\times$ three variance components-A, C, and E). A total of 13 of these 48 comparisons were significantly different between the models: the A component was significant in three comparisons, the $\mathrm{C}$ component was significant in seven comparisons, and the $\mathrm{E}$ was significant in three comparisons. Because we are examining standardized proportions of variance, however, if one of the variance components increases, then the other two correspondingly decrease.

It is instructive to examine the specific instances where the ET and twin models diverge. The first discrepancy occurred for drinking frequency in the Virginia males. Here, the genetic components from the ET model were significantly lower than A from the twin model, while the environmental components were significantly higher than $\mathrm{C}$ from the twin model. For drinking frequency in the Virginia females, the E component from the ET model was significantly larger than the $\mathrm{E}$ component from the twin model, with no differences in the A or C components. It is important to note that for drinking frequency in the Virginia sample, the cousin correlations (as can be seen in Figure 2) are a higher than would be expected, which influences the estimates of both the broad genetic factors and environmental factors.

There is also a discrepancy between the ET and twin models for age of first drink in the Australian sample. For males, the systematic environmental components in the ET model are higher than the $\mathrm{C}$ estimate from the twin, while the E estimate in the ET model is lower than the twin estimate. By contrast, for females, the systematic environmental components in the ET model are lower than the $\mathrm{C}$ estimate from the twin model. In this case, the $\mathrm{MZ}$ male correlations are substantially lower than we expected, as can be seen in Figure 2, though the correlations are consistent for $\mathrm{MZ}$ males across samples. Because of this, utilizing the genetic and environmental contributions from other family members likely provides a more realistic estimate of the environmental factors than we observe from the twin-only model.

In total, 7 of the 13 observed discrepancies between the ET and twin model are found for the number of drinks in the past week. Due to the question wording, we expected this variable to have a reasonable amount of measurement error, as is indicated by relatively large E components and correspondingly lower correlations between relatives. Again, most of the discrepancies between the ET and twin models were a function of differences in the environmental variance components. Furthermore, the distribution number of drinks consumed in the past week was skewed, and while this did not affect the broad conclusions about the mode of transmission, it could affect hypothesis testing between the ET and twin-only designs. 
Despite these somewhat minor differences, we conclude that the consistency between the estimates in the twin-only design and the sum of the parameters from the ET design is very high, often within a few percentage points. If the twin-only estimates are interpreted as the broad-sense heritability and environmental variance components, there is minimal deviation from the ET results. The ET model, however, provides enhanced specificity regarding the specific genetic or environmental variance components. In contrast with expectation regarding the confluence of $\mathrm{A}$ and $\mathrm{D}$, the observed deviations between the twin and ET models seem to focus on the environmental variance components, especially in the models for the number of drinks that the respondent consumed in the last week. Importantly, the differences between the ET and twin models do not appear to be systematic. Sometimes the ET parameter is higher than the corresponding twin estimate, while at other times it is lower. If the bias in the twin models was consistently higher (or lower) than the ET model, it would be cause for concern. In the current analyses, this is not the case, and we are not overly concerned.

Comparing the Australia and Virginia samples. The pattern of results was remarkably consistent across the two countries. The analyses focus on parameters that were significant in both samples, that is, the strongest and most replicable results. It is possible that in doing so we are overlooking findings that are specific to one sample and overemphasizing the similarity. In this section, we focus on these differences but reiterate that the differences between samples are minor.

As would be expected, the differences between the samples seem to focus on the environmental variance components. Specifically, for drinking quantity, the $\mathrm{S}$ and $\mathrm{T}$ parameters are larger for the Virginian females, $\mathrm{Sf}_{\mathrm{va}}=0.16$ $(95 \%$ CI $[0.10,0.20])$ and $\mathrm{Tf}_{\mathrm{va}}=0.08(95 \% \mathrm{CI}[0.01,0.17])$, than for the Australian females, $\mathrm{Sf}_{\mathrm{au}}=0.09(95 \% \mathrm{CI}[0.03$, $0.15])$ and $\mathrm{Tf}_{\mathrm{au}}=0.02(95 \% \mathrm{CI}[0.00,0.07])$. For drinking frequency, for both sexes, the $S$ parameters are larger in the Virginia sample, $\mathrm{Sm}_{\mathrm{va}}=0.18(95 \% \mathrm{CI}[0.10,0.29])$ and $\mathrm{Sm}_{\mathrm{va}}$ $=0.23(95 \% \mathrm{CI}[0.12,0.29])$, relative to the Australia sample, $\mathrm{Sm}_{\mathrm{au}}=0.06(95 \% \mathrm{CI}[0.01,0.15])$ and $\mathrm{Sf}_{\mathrm{au}}=0.09(95 \%$ CI $[0.02,0.16])$. Inversely, for age at first drink, the environmental factors, $\mathrm{T}$ for males and $\mathrm{S}$ for females, are larger in the Australia sample, $\mathrm{Tm}_{\mathrm{au}}=0.22(95 \%$ CI $[0.10,0.33])$ and $\left.\mathrm{Sf}_{\mathrm{au}}=0.23(0.10,0.36]\right)$, relative to the Virginia sample, $\mathrm{Tm}_{\mathrm{va}}=0.00(95 \% \mathrm{CI}[0.00,0.11])$ and $\mathrm{Sf}_{\mathrm{va}}=0.03(95 \% \mathrm{CI}$ $[0.00,0.16])$.

There was one situation where the genetic factors seemed to differ across the samples. Specifically, for the number of drinks consumed in the past week, the Australian females had a larger non-additive genetic variance component, $\mathrm{Df}_{\mathrm{au}}=0.30$ (95\% CI $\left.[0.19,0.43]\right)$, than their Virginia counterparts, $\mathrm{Df}_{\mathrm{au}}=0.02((95 \% \mathrm{CI}[0.00,0.13])$.
Cultural transmission. One of the (more interesting) factors that can be estimated in the ET model that cannot be estimated with twins alone is cultural transmission from parents to children. For three traits, cultural transmission significantly contributes to variance in the offspring's drinking behaviors: drinking quantity, drinking frequency, and the number of drinks in the last week. The pattern of results that emerges is quite interesting from a socialization perspective. For drinking quantity in both samples and drinking frequency in Virginia, the mother-to-daughter transmission appears to be driving cultural transmission. Alternatively, for the number of drinks consumed in the past week, within-sex (father-to-son and mother-todaughter) transmission appears to be important. In toto, it appears that insofar as these are environmental effects, children model their normal drinking behaviors on their same-sex parent, particularly females, notwithstanding differences due to genetic segregation.

Gene-environment covariation. With the ET model, it is possible to estimate passive gene-environment covariation. In four models, gene-environment covariation is significant: drinking quantity and frequency in the Virginia females and the number of drinks in the past week for the Virginia males and the Australian females (which is in the opposite direction). This significant, passive geneenvironment covariation implies that parental drinking behavior (which is a function of the parental genotype) creates an environment that is conducive to corresponding drinking behaviors in their offspring. Parents who have a higher genetic load for drinking create environments that encourage higher levels of drinking in the subsequent generation. While these effects are intriguing, it is important not to overemphasize these effects, as they are small, inconsistent, and have very large confidence intervals.

\section{Discussion}

The ET analysis revealed several interesting results. First, there were notable differences across the behaviors, with drinking quantity having a substantial amount of genetic variation but minimal systematic environmental variation, drinking frequency having a significant genetic and environmental variation, age at first drink having no significant genetic variation but $\mathrm{z}$ substantial systematic environmental variation, and the number of drinks in the last week having a substantial amount of unshared environmental variation.

These differences have several implications. When exploring the genetic and environmental factors that contribute to normal drinking behaviors, the choice of phenotype matters. While the phenotypes are related, empirically and theoretically, it is important to identify the specific behavior as some have larger or smaller contributions from genetic and environmental factors. This 
highlights the need to better understand the specific causal relationships between these variables. Specifically, these normal drinking behaviors are likely correlated at both the genetic and environmental levels, but there is the possibility of causal relationships between the phenotypes (Cramer et al., 2010). In doing so, it may be possible to more accurately examine the etiology of drinking behaviors.

Second, there was a large degree of consistency between the ET and twin-only models, supporting the convention of the interpretation of $\mathrm{A}$ in twin models as a broad genetic factor that incorporates both additive and non-additive genetic factors, and $\mathrm{C}$ in the twin model as a broad environmental factor that incorporates systematic environmental factors that contribute to a phenotype. The ET model provides enhanced specificity that allows researchers to make more nuanced conclusions about sources of variation and highlights new questions for future research.

For example, for drinking frequency and quantity, there was a substantial amount of non-additive genetic variance in females (but not males). One interpretation of this is that there is sex limitation whereby the type genetic factors are different in males and females. Another possibility is that the non-additivity is a function of the fact that the parentoffspring relationship is lower than what would be expected given additive genetic variance and cultural transmission, which may be particularly important for mother-daughter correlations. To compensate for this, the model partitions this variance into $D$. It is possible that this effect is driven by age-specific genetic variance. If there are age-specific genetic effects, twins who are the same age and siblings who are relatively close in age would be more correlated with each other than with their parents. While $\mathrm{D}$ is typically labeled dominance, it captures several types of genetic nonadditivity beyond simple dominance, such as epistasis or gene-by-age interactions (and other $\mathrm{G} \times \mathrm{E}$ interactions) that are non-additive genetic factors broadly defined. Relatedly, while there is no specific test for parent-child environmental differences, age-specific environmental effects would inflate the special twin environment factor because twins are more similar in age than they are to their siblings. Verhulst et al. (2014) suggested a method for testing for age-difference moderation in twin-sibling models, but the model has not been extended to other family members as assortative mating greatly complicates model expectations.

Third, there was a high degree of similarity between the Australian and Virginian samples, underscored by the very large sample sizes for both studies (Australia $\approx 20,000$ individuals from 8,019 families; Virginia $\approx 23,000$ from 6,042 families). As was implied by the phenotypic correlations and borne out by the model-fitting results, the same general pattern of results was found in both samples. There were a few places where the specific variance components differed across samples. Interestingly, discrepancies were primarily found at environmental rather than at the genetic levels. This is exactly where these behaviors would be expected to differ, given that drinking norms are different in the two countries. While these differences are statistically significant, the magnitude of the differences is relatively small and requires very large sample sizes to detect.

Further, there was a small but significant amount of cultural transmission, which was primarily a function of mother-to-daughter transmission. While several studies have demonstrated behavioral correlations between parents and children, in most cases, these associations confound potential vertical cultural transmission with genetic transmission (Ary et al., 1993; Bauman et al., 2001; Dielman et al., 1993; Duncan et al., 1994; Langhinrichsen et al., 1990; Lau et al., 1990; Weinberg et al., 1994; White et al., 2000). Specifically, most studies find that parent-child communication regarding alcohol behaviors and parental modeling of behavior has an influence on their offspring's behavior. However, studies that directly test for vertical cultural transmission in alcohol use (Koopmans \& Boomsma, 1996) or alcohol use disorders (Kendler et al., 1994) typically fail to find evidence for vertical cultural transmission over and above genetic transmission. There were a number of differences that increases the power in the current study relative to previous studies. First, the sample size here is much larger than previous investigations looking at normal drinking behavior and the current respondents were older, which increases the likelihood that people are at a stable level of drinking (Koopmans \& Boomsma, 1996). Second, previous studies focus on alcohol use disorders and the current study focuses on normal drinking behaviors, which are more prevalent. The increase in prevalence reduces the residual variance and increases the power of the analyses.

In addition, there was a substantial assortative mating for the alcohol behaviors. Drinking behaviors clearly matter in one's choice of spouse; for the current analysis, the important feature is the extent to which the assortative mating inflates the genetic or cultural transmission parameters. Because of the large spousal correlations and moderate Am, in the ET model, there is a small increase in A via assortment variance for drinking quantity in Virginian males and drinking frequency in Australian males (Baker et al., 1996). This was not significant for females, as the Af components were smaller and there is no inflation in the genetic component from $\mathrm{D}$ variance. For drinking frequency and quantity in the Virginian females, however, there is some inflation in the environmental transmission from assortative mating, consistent with mother-to-daughter cultural transmission. The influence of assortative mating on both the genetic and environmental variance components is fascinating and deserves more attention in the future.

\section{Limitations}

The analyses must be interpreted in light of two primary limitations. First, the current results do not take nonlinear effects of age into consideration. Specifically, it is 
possible that age-specific genetic or environmental effects could moderate the genetic or environmental variance components (Verhulst et al., 2014). Alternatively, cohort effects could affect the intergenerational covariance of drinking behaviors. Notably, most non-linear effects of age would appear as D or T, as was observed for females for several phenotypes. While all attempts were made to minimize the linear influence of age on the covariance between relatives, the present results should be seen as a first step towards understanding the complex intergenerational effects of genes and environments on normal drinking behaviors.

Second, there is a large amount of missing data, especially in the more distant familial relationships. The twins, who formed the core of the sample, were reasonably complete, but the children of the twins, as well as the spouses and siblings, were less well represented. Because there were 18 possible relatives, it is nearly impossible for any family to have all possible members. Specifically, the current analyses span three generations and allow the twins to have two brothers, two sisters, two sons (each), and two daughters (each). These would be very large families by modern standards. This may have influenced the correlation between cousins in the Virginia sample as the sparseness of the data can result in correlations that would not be expected for standard biometric analyses due, potentially, to chance observations. Importantly, there are structural reasons for some of the observed missingness.

\section{Implications and Future Directions}

The ET model provides a much more nuanced perspective than the twin-only design. This nuance highlights a large number of new questions about the parameters that cannot be estimated within the twin-only framework and the etiology of drinking behaviors. For example, exploring maternal and paternal genetic effects can be tested using the children-of-twins design, where adult twins and their offspring are necessary to examine the relationships. Another interesting direction for future research is the examination of assortative mating. In every drinking phenotype we examined, spousal correlations were highly significant, implying that spouses choose their mates based upon similar patterns of drinking behaviors. Because these phenotypes have an additive genetic variance component, assortative mating implies that DZ twins and other siblings are more similar genetically than would be assumed in the absence of assortative mating. Accordingly, assortative mating would be expected to inflate the common environmental variance component. This is exactly what happens for drinking quantity in the Virginia males. Specifically, the additive genetic variance from assortment is statistically significant and the common environmental variance component is attenuated in the extended twin model. Given that the shared environment is not significant in the twin model, however, tempers the conclusions we draw from this finding.

\section{Conclusions}

In this paper, we estimated the variance components for the ET model for four normal drinking behaviors in approximately 23,000 individuals from 6,042 twin families from Virginia and 20,000 individuals from 8,019 twin families in Australia. Comparisons between drinking phenotypes suggested that drinking quantity and drinking frequency were strongly influenced by genetic factors and to a lesser extent by shared environmental factors. The number of drinks an individual had in the previous week also showed a similar pattern of intergenerational transmission, with larger unique environmental variance components. Finally, the age of first drink showed a different pattern of transmission, being almost entirely a function of shared environmental variation, with no genetic factors significantly affecting alcohol onset. Furthermore, when comparing the parameters from the ET model with their analogues in the twin-only model, there were relatively few differences, and those that did exist were found in the shared environmental variance components. The benefits of the ET model, therefore, rest on the increased specificity in the parameters relative to their counterparts in the twin-only model. Finally, there were limited differences between the Australian and Virginian samples, with the small differences that were observed coming mainly from the environmental components. This implies that the genetic factors are quite similar across different cultures with different historical relationships with alcohol.

\section{Acknowledgments}

This research was funded by Australian NHMRC Grants 941177 and 971232 and by NIH Grants AA06781, AA07535, AA07728, GM30250, AG04954, MH40828, DA026119, and DA018673, and by a gift from R.J.R. Nabis. We would like to thank Louise Torten, Kathy Edwards, Theresa Pangan, John Pearson, and Olivia Zheng for assistance with data management. We would also like to acknowledge the AARP for assistance with twin ascertainment and Walter Nance and Linda Corey for making twins from the VA twin registry available to us.

\section{References}

Aitken, A. (1934). Note on selection from a multivariate normal population. Proceedings of the Edinburgh Mathematical Society, 4, 106-110.

Ary, D. V., Tildesley, E., Hops, H., \& Andrews, J. (1993). The influence of parent, sibling, and peer modeling and attitudes on adolescent use of alcohol. International Journal of the Addictions, 28, 853-880.

Australian Institute of Health and Welfare (AIHW) (2013). National Drug Strategy Household Survey (Detailed Report). Canberra, Australia: Author.

Baker, L. A., Treloar, S. A., Reynolds, C. A., Heath, A. C., \& Martin, N. G. (1996). Genetics of educational attainment in 
Australian twins: Sex differences and secular changes. Behavior Genetics, 26, 89-102.

Bauman, K. E., Ennett, S. T., Foshee, V. A., Pemberton, M., \& Hicks, K. (2001). Correlates of participation in a family-directed tobacco and alcohol prevention program for adolescents. Health Education \& Behavior, 28, 440461.

Boker, S., Neale, M., Maes, H., Wilde, M., Spiegel, M., Brick, T., ... Fox, J. (2011). Openmx: An open source extended structural equation modeling frame-work. Psychometrika, 76, 306-311.

Boker, S. M., Neale, M. C., Maes, H. H., Wilde, M. J., Spiegel, M., Brick, T. R., ... Brandmaier, A. (2012). OpenMx 1.2 user guide. Charlottesville, VA: Department of Psychology, University of Virginia.

Carmelli, D., Heath, A. C., \& Robinette, D. (1993). Genetic analysis of drinking behavior in World War II veteran twins. Genetic Epidemiology, 10, 201-213.

Clifford, C. A., Hopper, J. L., Fulker, D. W., \& Murray, R. M. (1984). A genetic and environmental analysis of a twin family study of alcohol use, anxiety, and depression. Genetic Epidemiology, 1, 63-79.

Cramer, A. O. J., Waldrop, L. J., Van Der Maas, H. L. J., \& Borsboom, D. (2010). Comorbidity: A network perspective. Behavioral and Brain Sciences, 33, 137-150.

Dielman, T. E., Butchart, A. T., \& Shope, J. T. (1993). Structural equation model tests of patterns of family interaction, peer alcohol use, and intrapersonal predictors of adolescent alcohol use and misuse. Journal of Drug Education, 23, 273316.

Duncan, T. E., Duncan, S. C., \& Hops, H. (1994). The effects of family cohesiveness and peer encouragement on the development of adolescent alcohol use: A cohort-sequential approach to the analysis of longitudinal data. Journal of Studies on Alcohol, 55, 588-599.

Eaves, L. (1979). The use of twins in the analysis of assortative mating. Heredity, 43, 399-409.

Eaves, L. J., Fulker, D. W., \& Heath, A. C. (1989). The effects of social homogamy and cultural inheritance on the covariances of twins and their parents: A LISREL model. Behavior Genetics, 19, 113-122.

Eaves, L. J., \& Heath, A. C. (1981). Sex-limitation and 'asymmetric' assortative mating. Progress in Clinical and Biological Research, 69, 73-86.

Eaves, L. J., Heath, A. C., \& Martin, N. G. (1984). A note on the generalized effects of assortative mating. Behavior Genetics, 14, 371-376.

Fulker, D. W. (1988). Genetic and cultural transmission in human behavior. In B. S. Weir, E. J. Eisen, M. M. Goodman, \& G. Namkoong ( Eds.), Proceedings of the Second International Conference on Quantitative Genetics (pp. 318-340). Sunderland, MA: Sinauer.

Gabrielli, W. F., \& Plomin, R. (1985). Drinking behavior in the Colorado Adoptee and Twin sample. Journal of Studies on Alcohol, 46, 24-31.

Grant, B. F. (1997). Prevalence and correlates of alcohol use and DSM-IV alcohol dependence in the United States: Re- sults of the National Longitudinal Alcohol Epidemiologic Survey. Journal of Studies on Alcohol, 58, 464-473.

Hawkins, J. D., Arthur, M. W., \& Catalano, R. F. (1995). Preventing substance abuse. In D. Farrington \& M. Tonry ( Eds.), Building a safer society: Strategic approaches to crime prevention (pp. 343-427). Chicago, IL: University of Chicago Press.

Hawkins, J. D., Catalano, R. F., \& Miller, J. Y. (1992). Risk and protective factors for alcohol and other drug problems in adolescence and early adulthood: Implications for substance abuse prevention. Psychological Bulletin, 112, 64105.

Hawkins, J. D., Graham, J. W., Maguin, E., Abbott, R., Hill, K. G., \& Catalano, R. F. (1997). Exploring the effects of age of alcohol use initiation and psychosocial risk factors on subsequent alcohol misuse. Journal of Studies on Alcohol, $58,280-290$.

Heath, A. C., Jardine, R., \& Martin, N. G. (1989). Interactive effects of genotype and social environment on alcohol consumption in female twins. Journal of Studies on Alcohol, 50, $38-48$.

Heath, A. C., \& Martin, N. G. (1988). Teenage alcohol use in the Australian twin register: Genetic and social determinants of starting to drink. Alcoholism Clinical and Experimental Research, 12, 735-741.

Heath, A. C., Meyer, J., Eaves, L. J., \& Martin, N. G. (1991). The inheritance of alcohol consumption patterns in a general population twin sample: I. Multidimensional scaling of quantity/frequency data. Journal of Studies on Alcohol, 52, 345-352.

Heath, A. C., Meyer, J., Jardine, R., \& Martin, N. G. (1991). The inheritance of alcohol consumption patterns in a general population twin sample: II. determinants of consumption frequency and quantity consumed. Journal of Studies on Alcohol, 52, 425-433.

Hopper, J. L., Hannah, M. C., Macaskill, G. T., \& Mathews, J. D. (1990). Twin concordance for a binary trait: III. A bivariate analysis of hay fever and asthma. Genetic Epidemiology, 7, 277-789.

Hopper, J. L., White, V. M., Macaskill, G. T., Hill, D. J., \& Clifford, C. A. (1992). Alcohol use, smoking habits and the adult Eysenck personality questionnaire in adolescent Australian twins [corrected]. Acta Geneticae Medicae et Gemellologiae (Roma), 41, 311-324.

Jardine, R., \& Martin, N. G. (1984). Causes of variation in drinking habits in a large twin sample. Acta Geneticae Medicae et Gemellologiae (Roma), 33, 435-450.

Kandel, D., Simcha-Fagan, O., \& Daves, M. (1986). Risk factors for delinquency and illicit drug use from adolescence to young adulthood. Journal of Drug Issues, 16, 67-90.

Kaprio, J., Hammar, N., Koskenvuo, M., Floderus-Myrhed, B., Langinvainio, H., \& Sarna, S. (1982). Cigarette smoking and alcohol use in Finland and Sweden: A cross-national twin study. International Journal of Epidemiology, 11, 378-386.

Kaprio, J., Koskenvuo, M., Langinvainio, H., Romanov, K., Sarna, S., \& Rose, R. J. (1987). Genetic influences on use and abuse of alcohol: A study of 5638 adult Finnish twin 
brothers. Alcoholism Clinical and Experimental Research, 11, 349-356.

Kaprio, J., Rose, R. J., Romanov, K., \& Koskenvuo, M. (1991). Genetic and environmental determinants of use and abuse of alcohol: The Finnish twin cohort studies. Alcohol and Alcoholism, 1(Supplement), 131-136.

Keller, M. C., \& Coventry, W. L. (2005). Quantifying and addressing parameter indeterminacy in the classical twin design. Twin Research and Human Genetics, 8, 201-213.

Keller, M. C., Medland, S. E., \& Duncan, L. E. (2010). Are extended twin family designs worth the trouble? A comparison of the bias, precision, and accuracy of parameters estimated in four twin family models. Behavior Genetics, 40, 377-393.

Keller, M. C., Medland, S. E., Duncan, L. E., Hatemi, P. K., Neale, M. C., Maes, H. H. M., \& Eaves, L. J. (2009). Modeling extended twin family data I: Description of the Cascade model. Twin Research and Human Genetics, 12, 8-18.

Kendler, K. S., Neale, M. C., Heath, A. C., Kessler, R. C., \& Eaves, L. J. (1994). A twin-family study of alcoholism in women. American Journal of Psychiatry, 151, 707-715.

Koopmans, J. R., \& Boomsma, D. I. (1996). Familial resemblances in alcohol use: Genetic or cultural transmission? Journal of Studies on Alcohol, 57, 19-28.

Lake, R. I., Eaves, L. J., Maes, H. H., Heath, A. C., \& Martin, N. G. (2000). Further evidence against the environmental transmission of individual differences in neuroticism from a collaborative study of 45,850 twins and relatives on two continents. Behavior Genetics, 30, 223-333.

Langhinrichsen, J., Lichtenstein, E., Seeley, J. R., Hops, H., Ary, D. V., Tildesley, E., \& Andrews, J. (1990). Parentadolescent congruence for adolescent substance use. Journal of Youth and Adolescence, 19, 623-635.

Lau, R. R., Quadrel, M. J., \& Hartman, K. A. (1990). Development and change of young adults' preventive health beliefs and behavior: Influence from parents and peers. Journal of Health and Social Behavior, 31, 240-259.

Loehlin, J. C. (1972). An analysis of alcohol-related questionnaire items from the national merit twin study. Annals of the New York Academy of Sciences, 197, 117-120.

Maes, H. H., Neale, M. C., \& Eaves, L. J. (1997). Genetic and environmental factors in relative body weight and human adiposity. Behavior Genetics, 27, 325-351.

Maes, H. H., Woodard, C. E., Murrelle, L., Meyer, J. M., Silberg, J. L., Hewitt, J. K., Rutter, M., ... Eaves, L. J. (1999). Tobacco, alcohol and drug use in eight- to sixteen-year-old twins: The Virginia twin study of adolescent behavioral development. Journal of Studies on Alcohol, 60, 293-305.

Neale, M. C., Hunter, M. D., Pritikin, J. N., Zahery, M., Brick, T. R., Kirkpatrick, R. M., ... Boker, S. M. (2015). Openmx 2.0: Extended structural equation and statistical modeling. Psychometrika, 81, 535-549.

Neale, M. C., \& Miller, M. B. (1997). The use of likelihoodbased confidence intervals in genetic models. Behavior Genetics, 27, 113-120.

Pearson, K. I. (1902). Mathematical contributions to the theory of evolution. XI. On the influence of natural selection on the variability and correlation of organs. Philosophical Transactions of the Royal Society of London, 60, 489-498.

Prescott, C. A., Hewitt, J. K., Heath, A. C., Truett, K. R., Neale, M. C., \& Eaves, L. J. (1994). Environmental and genetic influences on alcohol use in a volunteer sample of older twins. Journal of Studies on Alcohol, 55, 18-33.

Secretary of Health and Human Services (SHHS) (1997). Alcohol and Health: Ninth Special Report to the U.S. Congress from the Secretary of Health and Human Services. Washington, DC: U.S. Department of Health and Human Services.

Stallings, M. C., Hewitt, J. K., Beresford, T., Heath, A. C., \& Eaves, L. J. (1999). A twin study of drinking and smoking onset and latencies from first use to regular use. Behavior Genetics, 29, 409-421.

Substance Abuse and Mental Health Services Administration (SAMHSA) (2012). National Survey on Drug Use and Health (NSDUH). Rockville, MD: Author.

Truett, K. R., Eaves, L. J., Walters, E. E., Heath, A. C., Hewitt, J. K., Meyer, J. M., ... Kendler, K. S. (1994). A model system for analysis of family resemblance in extended kinships of twins. Behavior Genetics, 24, 35-49.

Van Eerdewegh, P. (1982). Statistical selection in multivariate systems with applications to quantitative genetics. $\mathrm{PhD}$ thesis, Washington University, St. Louis, MO, USA.

Verhulst, B., Eaves, L. J., \& Neale, M. C. (2014). Moderating the covariance between family member's substance use behavior. Behavior Genetics, 44, 337-346.

Weinberg, N. Z., Dielman, T. E., Mandell, W., \& Shope, J. T. (1994). Parental drinking and gender factors in the prediction of early adolescent alcohol use. International Journal of the Addictions, 29, 89-104.

White, H. R., Johnson, V., \& Buyske, S. (2000). Parental modeling and parenting behavior effects on offspring alcohol and cigarette use. A growth curve analysis. Journal of Substance Abuse, 12, 287-310. 